Socio-emotional problems and learning skills of Roma and recently arrived refugee children in German elementary schools

Sandy Chwastek, Birgit Leyendecker, Julian Busch

Faculty of Psychology, Child and Family Research, Ruhr-University Bochum

Correspondence concerning this article should be addressed to Sandy Chwastek, Ruhr University Bochum, Faculty of Psychology, Child and Family Research, GAFO 04/609, Universitätsstraße 150, 44780 Bochum, +49 (0)234-32-26054, Sandy.Chwastek@rub.de

The present manuscript is the revised version of an article that underwent a peerreview process. If possible, please consider to cite the published version of the article.

\title{
ORCID
}

Sandy Chwastek, https://orcid.org/0000-0002-4195-3882

Birgit Leyendecker, http://orcid.org/0000-0003-1301-8069

Julian Busch, http://orcid.org/0000-0003-4626-7045 


\begin{abstract}
Background: In Germany, many recently arrived and minority families live in multi-ethnic, high-poverty districts. Multiple risk factors threaten their children's development.

Aims: We examined the socio-emotional problems of these children in relation to their academic learning skills and executive functioning.
\end{abstract}

Method: We compared teacher-rated socio-emotional problems of $n=112$ Roma children (90\% foreign-born), $n=101$ refugee children (all foreign-born), and $n=56$ German-born immigrant children (age in months: $M=99.66, S D=13.61$ ) between groups and to norm data. We related socio-emotional problems to receptive vocabulary, cognitive reasoning, motor skills, and executive functioning in $n=83$ refugee and Roma children.

Results: Roma children showed higher rates above cutoff than norm data in all subscales, more problems in all subscales but emotional symptoms than immigrant children, and more hyperactivity/inattention and peer problems than refugee children. Refugee children showed higher rates above cutoff than norm data in all subscales and more peer problems than immigrant children. Academic learning skills were overall below average among recently arrived children. Prosocial behavior was positively linked to fine motor skills. Other socioemotional problems were not linked to academic learning skills and executive functioning. Gross and visuo-motor skills correlated positively with other academic learning skills.

Limitations: We analyzed cross-sectional data. We did not include risk factors or nonimmigrant German children.

Conclusion: The heightened socio-emotional problems and low academic learning skills of refugee and particularly Roma children in high-poverty districts could jeopardize their educational trajectories. Additional support measures could increase their chances for educational participation.

Keywords: mental health, primary education, minority, SDQ, behavior problems 


\section{Socio-emotional problems and learning skills of Roma and recently arrived refugee children in German elementary schools}

During the past years, the state North Rhine-Westphalia (NRW) received more than one-fifth of all asylum-seekers in Germany (MKFFI, 2019). Recently immigrated families are likely to settle in multi-ethnic, high-poverty urban districts. Many families in these districts do not speak German, are unfamiliar with the German bureaucratic and education system, and lack the resources to support early learning. Two of the largest groups in urban areas of NRW are recently arrived refugee and Roma minority families. The challenging migration-related experiences (Bronstein \& Montgomery, 2011) potentially put the children at risk of not reaching school readiness and not keeping pace in school. The relations of socio-emotional adjustment and academic learning skills among different groups of recently arrived and minority children are still understudied.

\section{Shared risk factors}

Both recently immigrated refugee and Roma minority families in these districts are likely to share similar environments and post-migration factors that put their educational trajectories at risk. For example, a low socioeconomic status and associated living conditions have been linked to lower language skills and lower executive functioning (EF; Greenfader, 2019), lower cognitive and social outcomes (Berry et al., 2016), and a higher risk to develop socio-emotional problems (Araújo Dawson \& Williams, 2008; Solari \& Mare, 2012). Other post-migration factors that were found to influence the socio-emotional adjustment of recently arrived refugee children were negative parenting and mother's psychological distress (Sim et al., 2018), father's presence on arrival, stability in school and home environments, financial stability, and external community support (Zwi et al., 2018). However, evidence also suggests that some risk factors differ between both groups.

\section{Refugee children}

Flight experiences put refugee children's development and mental health additionally at risk (Bronstein \& Montgomery, 2011). Increased levels of socio-emotional problems were repeatedly found in recently arrived refugee children in different resettlement countries (Borsch et al., 2018; Buchmüller et al., 2019; Fazel et al., 2012; Kien et al., 2018). Refugee children's socio-emotional problems have been linked to lower academic achievement in adolescents (Wong and Schweitzer, 2017) and elementary school-aged children (Özmen, 2020). Also, lower academic learning skills were found in refugee children when compared to 
non-immigrant peers (Pellizzoni et al., 2020). In a literature review on elementary schoolaged refugee children, however, their time spent in the host country and their arrival time during the academic year influenced their academic achievements (Aghajafari et al., 2020). Arriving after elementary school enrolment was also linked to worse academic outcomes in ninth grade in immigrant students (Lundahl \& Lindblad, 2018). Additionally, Lau et al. (2018) found good socio-emotional adjustment two to three years after arrival. These findings suggest that recently arrived refugee children initially show low socio-emotional adjustment and academic learning skills, but can adapt over time.

\section{Roma minority children}

Roma minority children face different additional risk factors. The majority of Roma families are legal EU immigrants and therefore not eligible for the support asylum-seekers receive. Across Europe, Roma children face extreme poverty and poor education (Milcher, 2006). In several European countries, a substantial proportion of Roma children do not enroll in the education system or drop out, spending only about half of the national average years in the education systems (Bennett, 2012). Roma parents are likely to lack information on the national education system (Dimitrova et al., 2018) and one-third of the Roma adults who grew up in Germany are illiterate (Strauß, 2021). While many refugee adolescents reported high educational aspirations (e.g., Stevenson \& Willot, 2007), this is less likely the case for Roma parents (Dimitrova et al., 2018). Additionally, Buchmüller and colleagues (2019) found heightened levels of socio-emotional problems in Roma children in Germany. In sum, evidence suggests that Roma children live in similar circumstances as refugee children do, yet likely without the resources many refugee children have.

\section{Socio-emotional problems and academic learning skills}

As heightened socio-emotional problems and lower academic learning skills were found in refugee and partly in Roma children, the question arises whether these are related to each other. Academic learning skills refer to a set of within-child developmental capacities that are necessary for progressing academically in education contexts. Such domains typically include motor, language, and cognitive development (High, 2008).

In majority populations, previous studies found links between socio-emotional problems and academic learning skills such as language skills (Arnold et al., 2012; Bornstein et al, 2013; Menting et al. 2010; Seguin et al., 2009), while other studies did not (Gooch et al., 2016; Karasinski, 2015; Nelson et al., 2016) or only for children of certain ages (Helland et 
al., 2018). In Latinx minority children in the U.S., language skills were not linked to socioemotional problems at school entry (Greenfader, 2019) and only to externalizing, but not internalizing, symptoms in elementary school-aged children (Araújo Dawson \& Williams, 2008). Socio-emotional problems were also related to EF in children aged four to seven (Gooch et al., 2016), in elementary school-aged children (Maasalo et al., 2020; Wang \& Liu, 2020), and Latinx children in the U.S. at school entry (Greenfader, 2019). A meta-analysis also negatively linked EF to symptoms of Attention-Deficit/Hyperactivity Disorder in schoolaged children (Martinussen et al. 2005). Also, poorer mathematical skills were linked to socio-emotional problems in preschool-aged children (Arnold et al., 2012; Dobbs et al., 2006), but not in students with emotional disturbances (Nelson et al., 2006). Additionally, a limited number of studies suggest links between different domains of academic learning skills in pre- and elementary school-aged children, but no such evidence does yet exist for refugee or minority populations. Language skills were repeatedly linked to motor skills (Becker et al., 2014; Roebers et al., 2014) and EF (Gooch et al., 2016; Tran et al., 2018). Additionally, motor skills were related to cognitive ability (Roebers et al., 2013) and EF (Becker et al., 2014).

While EF was linked to non-verbal intelligence (Roebers et al., 2013) and mathematical skills (Purpura et al., 2017), other studies found neither relations between EF and language skills in preschool- and school-aged children (Karasinski, 2015; Purpura et al., 2017) nor academic mastery in children of Latinx farmworkers in the U.S. (Taylor et al., 2019).

\section{This study}

Previous work suggests heightened levels of socio-emotional problems and low educational achievement among refugee and Roma children while comparative studies are yet limited. Both groups often live in high-poverty, multi-ethnic districts, but likely have different resources. Our study examines socio-emotional problems in Roma, recently arrived refugee, and German-born immigrant children in multi-ethnic, high-poverty districts and relates these to their academic learning skills and EF. We hypothesize that 1) Roma and refugee children show more socio-emotional problems and lower academic learning skills when compared to norm data as well as to German-born immigrant children; 2) that more socio-emotional problems are related to lower receptive vocabulary, cognitive reasoning, motor skills, and EF; and 3 ) that the different components of academic learning skills and EF are positively related to each other. 


\section{Methods}

\section{Participants and procedure}

We collected data from $N_{\text {total }}=305$ children attending grades one to four in two elementary schools located in the Ruhr area during the first two weeks of March 2020. Both schools were situated in high-poverty, multi-ethnic urban districts. Class teachers provided information on children's socio-emotional problems and demographic data. Trained research assistants additionally collected data on children's academic learning skills with $n=104$ children of one school. Further testing had to be canceled due to the Covid-19 lockdown in mid-March 2020. Thus, we had a teacher-report dataset with demographic and socioemotional problems data (i.e., $S D Q$ sample) and a subsample with additional data on academic learning skills (i.e., subsample). All children of both schools were initially eligible to participate in our study if their parents signed an informed consent form beforehand. The internal review board of the Faculty of Psychology at the Ruhr-University Bochum approved the study protocol.

We excluded $n=32$ children with German mother tongue and $n=4$ recently arrived children from EU countries who were neither Roma nor refugee children. Thus, the SDQ sample consisted of $N=269$ children ( $M=99.66$ months, $S D=13.61 ; 48.70 \%$ female) including $n=112$ Roma minority children (all but 10\% were born abroad), $n=101$ recently arrived refugee children, and $n=56$ German-born immigrant children with a non-German mother tongue. The majority of the refugee children spoke Arabic at home (59.41\%), another $10.89 \%$ came from Iraq or Syria and spoke Kurdish, Farsi, or Hebrew. The remaining refugee children spoke a total of 10 different languages, most of these children were from African or Asian countries. Children from the three groups did not differ regarding age, gender, and distribution across grades one to four. The mean number of years the families had spent in Germany was $M=3.82(S D=1.80)$ for recently arrived refugee children and $M=4.79(S D=$ 2.10) for Roma children. All three groups differed regarding children's rates of preschool attendance, $X^{2}(2)=43.911, p<.001$, and parents' literacy, $H(2)=28.16, p<.001$, but not regarding the number of siblings $H(2)=3.929, p=.14$ (Table 1 ).

In the subsample, we excluded $n=5$ children with German mother tongue and $n=16$ German-born immigrant children, resulting in $n=83$ Roma and refugee children. Consistent with our study scope, we thus ensured that the observations on academic learning skills and their relations to socio-emotional problems exclusively referred to recently arrived refugee and Roma children. When comparing the subsample to the refugee and Roma children in the 
SDQ sample $(n=213)$, there were no differences regarding rates of preschool attendance, $X^{2}(1)=0.310, p=.578$, parents' literacy, $U=3,170, p=.22$, or number of siblings, $U=6,267$, $p=.799$.

\section{Measurement}

\section{Socio-emotional problems}

Class teachers reported on children's socio-emotional problems using the German adaptation of the Strengths and Difficulties Questionnaire (SDQ; Goodman, 1997). It consists of five subscales (hyperactivity/inattention, conduct problems, emotional symptoms, peer relationship problems, and prosocial behavior) with five items each, which are computed into sum scores. The 3-point Likert scale ranges from $0=$ "absolutely not true" to 2 = "absolutely true". Additionally, all problem subscales are summarized into a total difficulties score. Cronbach's Alphas in the SDQ sample ranged from $\alpha=.73$ ( $\alpha=.80$ in the subsample) for peer relationship problems to $\alpha=.88$ for hyperactivity/inattention $(\alpha=.88$ in the subsample).

\section{Academic learning skills}

Research assistants tested each child individually following a standardized assessment protocol. German language skills were measured via receptive vocabulary with a tablet-based version of the German adaptation (Lenhard et al., 2015) of the 4th edition of the Peabody Picture Vocabulary Test. The child has to match a spoken word to one of four pictures. We used the subtest Object Assembly of the German version of the Wechsler Preschool and Primary Scale of Intelligence-III (Petermann \& Lipsius, 2009) to measure visual concept formation by the number and accuracy of combined puzzle pieces as an indicator of cognitive reasoning. For measuring motor skills, we used gross, fine, and visuo-motor skills subscales of the Intelligence and Development Scales (Grob et al., 2009). The gross motor subscale includes balancing on and jumping across a rope as well as throwing and catching a ball. The fine motor subscale includes threading with beads and the visuo-motor subscale copying geometrical pictures with a pencil.

\section{Executive functioning}

We used the tablet-based Hearts and Flowers Task (Diamond et al., 2007), an alternate Dots task (Davidson et al., 2006) version, to measure cognitive flexibility, inhibitory control, and working memory. The child has to press either a button on the same or opposite side as a stimulus on the screen, or combine both (mixed condition). We used an efficiency score reflecting all three subcomponents (Hughes \& Devine, 2019). It is the quotient of the 
total number of correct trials in the mixed condition divided by the total response time in the mixed trials and technically ranges from about 0.015 to 33 . We cannot reference EF to norm data.

\section{Statistical analysis}

All analyses were conducted in $R$ using packages car, gvlma, hmisc, ltm, and psych. We used raw scores of academic learning skills. First, we compared SDQ scores to German norm data based on a community sample of children aged six to 16 (Woerner et al., 2004). Therefore, we compared proportions above cutoff values between our study groups and the norm data, splitting scores into the three categories normal, borderline, and abnormal. We also compared academic learning skills to norm data as described in the user manuals. Next, using hierarchical multiple linear regression modeling, we compared SDQ scores between dummycoded groups and linked SDQ scores in the subsample to academic learning skills and EF, controlling for age and gender. We used the functions gvlma and vif to examine assumptions for linear modeling. We used bivariate correlations to interrelate academic learning skills and EF. As theory substantiated directions for our hypotheses, we used one-tailed $p$-values $(\alpha=$ $.05)$. Holm-Bonferroni correction (Holm, 1979) was used to control $\alpha$-level error inflation.

\section{Results}

Hypothesis 1) Table 2 shows descriptive information on the SDQ subscales and proportions of children scoring above the cutoff for abnormal socio-emotional problems. Table 3 shows descriptive information on academic learning skills and their comparisons to norm data. Three gross motor items of one child were missing. The child was excluded from the analysis of the gross and total motor scores. There were no missing values in the SDQ subscales or other academic learning skills data. We found no differences for age, gender, and the SDQ subscales between the SDQ sample and the subsample using unpaired $t$-tests. Statistical assumptions were overall acceptable across all hierarchical regression models.

Proportions of Roma children scoring in the abnormal range were descriptively above those of the norm data in all subscales and total difficulties. Proportions of refugee children scoring in the abnormal range were above those of the norm data in all subscales, but not total difficulties. Roma children showed more hyperactivity/inattention, conduct problems, and peer problems, and less prosocial behavior when compared to immigrant children (Table 4). Additionally, Roma children showed more hyperactivity/inattention and peer problems when 
compared to refugee children. Refugee children also showed more peer problems when compared to immigrant children.

Based on norm data, children in the subsample scored below average for most academic learning skills (Table 3). The majority of children scored below or far below average in receptive vocabulary and visuo-motor skills. Most children scored average in gross and fine motor skills, however, more than $20 \%$ scored below or far below average in each measure. In cognitive reasoning, most children scored about average.

Hypothesis 2) We did not find any relations between socio-emotional problems, academic learning skills, and EF, except for prosocial behavior positively relating to fine motor skills (Table 5). In the hierarchical regression analyses, we also found influences of the covariates age and gender on the child outcomes (Tables 4 and 5).

Hypothesis 3) We found relations between the different academic learning skills and EF (Table 6). After $\alpha$-error adjustment, visuo-motor skills were positively correlated with receptive vocabulary $(p=.010)$, and cognitive reasoning $(p<.001)$. Additionally, gross motor skills were positively correlated with $\mathrm{EF}(p=.013)$, fine motor skills $(p=.009)$, and visuomotor skills $(p=.009)$.

\section{Discussion}

This study aimed to comparatively identify socio-emotional problems of recently arrived refugee and Roma children attending elementary schools in multi-ethnic, high-poverty districts. We moreover related their socio-emotional problems to their academic learning skills and EF. We found heightened socio-emotional problems in Roma and refugee children when compared to German-born immigrant children and norm data. Roma children also showed more hyperactivity/inattention and peer problems when compared to refugee children. Descriptive findings indicated low academic learning skills. Contrary to our expectations, socio-emotional problems were mostly unrelated to academic learning skills. Gross motor skills and visuo-motor skills were related to other academic learning skills.

\section{Socio-emotional problems}

As expected in our first hypothesis, we found that Roma and refugee children showed heightened socio-emotional problems when compared to norm data, and partly when compared to immigrant children. This is in line with previous literature (Buchmüller et al., 2019; Fazel et al., 2012; Kien et al., 2018). In addition, a higher percentage of immigrant children scored above SDQ cutoff values than norm data in all subscales except for peer 
problems. These findings suggest that, in addition to pre-migration experiences, postmigration living conditions and family factors may influence children's socio-emotional adjustment. This is supported by previous studies that linked risk factors related to living in multi-ethnic, high-poverty districts during post-migration periods to heightened socioemotional problems (Berry et al., 2016; Solari \& Mare, 2012).

The between-group differences in our sample suggest that the Roma and refugee children likely face similar sets of contextual risk factors in their neighborhoods, but different levels of family resources or distinct migration experiences. Previous literature supported the idea that different profiles of risk and protective factors among groups of recently arrived children variably influence their academic achievements and socio-emotional problems (Berry et al., 2016; Solari \& Mare, 2012). This might explain why Lau and colleagues (2018) found high socio-emotional adjustment levels for refugee children, although these had lived in the host country for shorter periods than our sample. The children in Lau and colleagues' (2018) sample were already more proficient in the host language, lived in relatively stable conditions, and received governmental support. In contrast, the refugee children in our sample lived in less stable conditions and had lower German proficiency levels, and the Roma families were not eligible for programs available to refugees. This could further explain their heightened levels of socio-emotional problems.

Our findings suggest that different groups of immigrant children in high-poverty, multi-ethnic districts, on average, vary in their mental health risk profiles, with Roma children being at highest risk, followed by refugee children. Indicators of socioeconomic status were substantially lower for Roma children than for refugee children. Roma children in our study were more likely to not have attended preschool and to have two illiterate parents. This is consistent with the findings of other studies that Roma parents likely lack the resources needed to support their children's school adjustment and academic learning (Dimitrova et al., 2018; Milcher, 2006). Compared to the Roma children, the refugee children in our study were more likely to have attended preschool and almost all refugee children had at least one literate parent. Except for peer problems, we found no differences in socio-emotional problems between refugee children and immigrant children. These findings are in line with other studies suggesting that family resources could buffer the effects of pre- and peri-migration experiences on socio-emotional problems (Fazel et al., 2012).

Socio-emotional problem profiles of refugee children differed from those of immigrant and Roma children. Refugee children tended to have average-level total difficulties 
while showing high-level problems in few distinct subscales. Thus, more refugee children tended to have heightened problems in only one or two subscales, which also differed from child to child. In contrast, those Roma and immigrant children with socio-emotional difficulties tended to have increased symptom levels in several subscales yielding increased levels of total difficulties for these children. Likely, punctual adverse experiences thus lead to different patterns of socio-emotional problems than permanent exposure to low resources and multiple risk factors. The refugee children were not necessarily permanently exposed to low family resources or challenging neighborhoods such as some Roma or immigrant children but might have been exposed to more severe flight-related experiences for a shorter period, before living in the same post-migration surroundings.

We found no group differences for emotional symptoms. This is in contrast to other studies that found higher levels of emotional problems for refugee children (e. g., Kien et al., 2018). Several factors might have contributed to this. First, all other SDQ subscales reflect better observable behaviors in education settings. Teachers might focus on problems that are more easily observed and potentially more relevant for class functioning. Second, the children in our study were younger than children in most studies. It remains unclear whether migration-related experiences affect older children differently than younger age groups and how this might reflect in their behavior. Third, child behavior likely differs between school and family contexts, as discrepancies between ratings of different informants were found (Achenbach et al., 1987). Therefore, future research should consider contexts beyond classrooms and involve multi-informant approaches to receive a more comprehensive picture of children's well-being.

In the group of immigrant children, peer problems were unexpectedly low. From a non-deficit-oriented perspective, children growing up in these ethnically diverse neighborhoods could have learned to better manage challenging social situations with other culturally and linguistically diverse children. Recently arrived refugee and Roma children might still need time to accustom to their new environments, both in Germany and after enrolment into elementary school. Their higher peer problems likely reflect, to some extent, the adaptation process to the new social contexts.

\section{Academic learning skills}

Descriptive analyses yielded low academic learning skills for refugee and Roma children when compared to norm data. This is in line with previous literature (Pellizzoni et al., 2020) and shows that these children are at risk of not keeping pace in school. Presumably, 
certain risk factors and a lack of resources (Dimitrova et al., 2018; Strauß, 2021) might hamper child development. The children scored especially low in receptive vocabulary and visuo-motor skills, which provide the basis for writing skills. Writing, in turn, feedbacks into vocabulary building. From a different perspective, the low receptive vocabulary scores are not surprising as the children in our study either arrived recently with their mother tongues not being German or were of Roma descent with overall higher levels of parental illiteracy and lower rates of preschool attendance.

Contrary to our second hypothesis, SDQ subscales were mostly unrelated to academic learning skills and EF in recently arrived refugee and Roma children. Previous literature, however, yielded mixed results on whether such relations exist (e. g., Arnold et al., 2012; Dobbs et al., 2006) or not (e. g., Helland et a., 2017; Karasinski, 2015). Notably, some of those studies built on teacher-biased outcomes such as grades. Such variables are generally biased by teachers' perceptions, teacher-student relationships, and students' socio-emotional behaviors. In our study, we assessed academic learning skills, which are independent of teacher ratings and build the basis for constructs used in other studies. Another reason for no relations in our study could be that teachers of both schools were experienced in teaching refugee and Roma children. Therefore, they might be more successful in fostering academic learning skills despite children's increased levels of socio-emotional problems.

Regarding our third hypothesis, visuo-motor skills correlated positively with cognitive reasoning and receptive vocabulary. The second link is in line with the often-reported lower writing skills in recently arrived children, as drawing geometric figures and writing have a common basis (i.e., controlling a pen) and writing improves the vocabulary. Furthermore, we assumed that low language skills might hamper school adaptation and thus lead to lower academic learning skills and more socio-emotional problems. However, vocabulary was mostly unrelated to the other constructs. Some measures might not correlate, as they do not have a common basis or links in a way that academic outcomes do (e.g., vocabulary is not needed for puzzling figures, but reading skills facilitate the understanding of mathematical tasks). Thus, socio-emotional problems and academic learning skills as measured in our study might be important for actual academic outcomes, but not necessarily influence each other. Future research should investigate their influence on academic skills. Surprisingly, we also found no interrelations with EF, except for gross motor skills. This finding is supported by one study (Taylor et al., 2019) but does not replicate the findings of several other studies (e. g., Gooch et al., 2016; Tran et al., 2018). 


\section{Limitations and future research}

We only collected cross-sectional data. Longitudinal data would allow to further examine how socio-emotional problems and academic learning skills influence academic development and shape educational trajectories. Also, we only considered few risk factors and did not capture their influence on the outcomes between groups. Refugee- or minority-specific factors, but also additional post-migration living conditions could be linked to heightened socio-emotional problems and lower academic learning skills. Future research should further investigate such living conditions and risk profiles among refugee and Roma children and deepen the understanding of children's differential socio-emotional problems profiles. Finally, we cannot preclude that the teachers perceived refugee and Roma children as more socioemotionally challenged when compared to immigrant children due to teacher bias, as previous literature suggests (Chwastek et al., 2021).

\section{Conclusion}

We found that especially Roma and - albeit to a lesser extent - refugee children have heightened socio-emotional problems and overall low academic learning skills. Our findings suggest that these could be related to certain risk- and family factors (e. g., literacy of parents or preschool attendance). Overall, our findings suggest that refugee and Roma children need additional socio-emotional and academic support to thrive within the German education system.

\section{Acknowledgements}

\section{Conflict of Interest}

We have no conflicts of interest to disclose.

\section{Publication Ethics}

The internal review board of the Faculty of Psychology at the Ruhr University Bochum approved the study protocol.

\section{Funding}

This study was supported by the educational trust fund RuhrFutur through a grant to Julian Busch and Birgit Leyendecker. 


\section{References}

Achenbach, T. M., McConaughy, S. H., \& Howell, C. T. (1987). Child/adolescent behavioral and emotional problems: Implications of cross-informant correlations for situational specificity. Psychological Bulletin, 101(2), 213-232. https://doi.org/10.1037/00332909.101.2.213

Aghajafari, F., Pianorosa, E., Premji, Z., Souri, S., \& Dewey, D. (2020). Academic achievement and psychosocial adjustment in child refugees: a systematic review. Journal of Traumatic Stress, 33(6), 908-16. https://doi.org/10.1002/jts.22582

Araújo Dawson, B., Williams, S.A. (2008). The impact of language status as an acculturative stressor on internalizing and externalizing behaviors among Latino/a children: A longitudinal analysis from school entry through third grade. Journal of Youth and Adolescence, 37, 399-411. https://doi.org/10.1007/s10964-007-9233-z

Arnold, D. H., Kupersmidt, J. B., Voegler-Lee, M. E., \& Marshall, N. A. (2012). The association between preschool children's social functioning and their emergent academic skills. Early Childhood Research Quarterly, 27(3), 376-86.

https://doi.org/10.1016/j.ecresq.2011.12.009

Becker, D. R., Miao, A., Duncan, R., \& McClelland, M. M. (2014). Behavioral self-regulation and executive function both predict visuomotor skills and early academic achievement.

Early Childhood Research Quarterly, 29(4), 411-24.

https://doi.org/10.1016/j.ecresq.2014.04.014

Bennett, J. (2012). Roma Early Childhood Inclusion: The RECI Overview Report. Budapest: Open Society Foundation, Roma Education Fund, UNICEF.

Berry, D., Blair, C., Willoughby, M., Garrett-Peters, P., Vernon-Feagans, L., Mills-Kooncee, W. R., \& The Family Life Project Key Investigators (2016). Household chaos and children's cognitive and socio-emotional development in early childhood: Does childcare play a buffering role?, Early Childhood Research Quarterly, 34(1), 115-27. https://doi.org/10.1016/j.ecresq.2015.09.003

Bornstein, M. H., Hahn, C. S., \& Suwalsky, J. T. (2013). Language and internalizing and externalizing behavioral adjustment: Developmental pathways from childhood to adolescence. Development and psychopathology, 25(3), 857-78. 
Borsch, A. S., de Montgomery, C. J., Gauffin, K., Eide, K., Heikkilä, E., Smith Jervelund, S (2018). Health, education and employment outcomes in young refugees in the nordic countries: A systematic review. Scandinavian Journal of Public Health, 47(7), 735-47. https://doi.org/10.1177/1403494818787099

Bronstein, I., \& Montgomery, P. (2011). Psychological distress in refugee children: A systematic review. Clinical Child and Family Psychology Review, 14, 44-56. https://doi.org/10.1007/s10567-010-0081-0

Buchmüller, T., Lembcke, H., Ialuna, F., Busch, J., \& Leyendecker, B. (2019). Mental health needs of refugee children in specialized early education and care programs in Germany. Journal of Immigrant and Minority Health, 22(1), 22-33. https://doi:10.1007/s10903-019$\underline{00896-4}$

Chwastek, S., Leyendecker, B., Heithausen, A., Ballero Reque, C., \& Busch, J. (2021). Preschool teachers' stereotypes and self-efficacy are linked to perceptions of behavior problems in newly arrived refugee children. Frontiers in Psychiatry, 11.

https://doi.org/10.3389/fpsyt.2020.574412

Davidson, M. C., Amso, D., Anderson, L. C., \& Diamond, A. (2006). Development of cognitive control and executive functions from 4 to 13 years: Evidence from manipulations of memory, inhibition, and task switching. Neuropsychologia, 44(11), 2037-78. https://doi.org/10.1016/j.neuropsychologia.2006.02.006

Diamond, A., Barnett, W. S., Thomas, J., \& Munro, S. (2007). Preschool program improves cognitive control. Science, 318(5855), 1387-8. https://doi.org/10.1126/science.1151148

Dimitrova, R., Ferrer-Wreder, L., \& Ahlen, J. (2018). School climate, academic achievement and educational aspirations in Roma minority and Bulgarian majority adolescents. Child \& Youth Care Forum, 47(5), 645-58. https://doi.org/10.1007/s10566-018-9451-4

Dobbs, J., Doctoroff, G. L., Fisher, P. H., \& Arnold, D. H. (2006). The association between preschool children's socio-emotional functioning and their mathematical skills. Journal of Applied Developmental Psychology, 27(2), 97-108.

https://doi.org/10.1016/j.appdev.2005.12.008

Fazel, M., Reed, R. V., Panter-Brick, C., \& Stein, A. (2012). Mental health of displaced and refugee children resettled in high-income countries: Risk and protective factors. The Lancet, 379(9812), 266-82. https://doi.org/10.1016/S0140-6736(11)60051-2 
Gooch, Thompson, Nash, Snowling, \& Hulme (2016). The development of executive function and language skills in the early school years. Journal of Child Psychology and Psychiatry, 57(2), 180-7. https://doi.org/10.1111/jepp.12458

Goodman, R. (1997). The Strengths and Difficulties Questionnaire: A research note. Journal of Child Psychology and Psychiatry, 38(5), 581-6. https://doi.org/10.1111/j.14697610.1997.tb01545.x

Greenfader, C. M. (2019). What is the role of executive function in the school readiness of Latino students? Early Childhood Research Quarterly, 49, 93-108. https://doi.org/10.1016/j.ecresq.2019.02.011

Grob, A., Meyer, C. S., \& Hagmann-von Arx, P. (2009). Intelligence and Development Scales (IDS). Intelligenz- und Entwicklungsskalen für Kinder von 5-10 Jahren. Bern: Hans Huber.

Helland, S., Røysamb, E., Wang, M., \& Gustavson, K. (2018). Language difficulties and internalizing problems: Bidirectional associations from 18 months to 8 years among boys and girls. Development and Psychopathology, 30(4), 1239-52.

https://doi.org/10.1017/S0954579417001559

High, P. C. (2008). School Readiness. Pediatrics, 121(4), e1008-e1015. https://doi.org/10.1542/peds.2008-0079

Holm, S. (1979). A simple sequentially rejective multiple test procedure. Scandinavian Journal of Statistics, 6(2), 65-70.

Hughes, C., \& Devine, R. T. (2019). For better or for worse? Positive and negative parental influences on young children's executive function. Child Development, 90(2), 593-609. https://doi.org/10.1111/cdev.12915

Karasinski, C. (2015). Language ability, executive functioning and behaviour in school-age children. International Journal of Language \& Communication Disorders, 50(2), 144-50. https://doi.org/10.1111/1460-6984.12104

Kien, C., Sommer, I., Faustmann, A., Gibson, L., Schneider, M., Krczal, E., Jank, R., Klerings., I., Szelag, M., Kerschner, B., Brattström, P., \& Gartlehner, G. (2018). Prevalence of mental disorders in young refugees and asylum seekers in European Countries: A systematic review. European Child \& Adolescent Psychiatry, 28(10), 1295310. https://doi.org/10.1007/s00787-018-1215-z 
Lau, W., Silove, D., Edwards, B., Forbes, D., Bryant, R., McFarlane, A., Hadzi-Pavlovic, D., Steel, Z., Nickerson, A., Van Hooff, M., Felmingham, K., Cowlishaw, S., Alkemade, N., Kartal, D., O’Donnell, M. (2018). Adjustment of refugee children and adolescents in Australia: outcomes from wave three of the Building a New Life in Australia study. BMC Medicine, 16(157), 1-17. https://doi.org/10.1186/s12916-018-1124-5

Lenhard, A., Lenhard, W., Segerer, R., \& Suggate, S. (2015). Peabody Picture Vocabulary Test - 4. Ausgabe: Manual. Frankfurt am Main: Pearson.

Lundahl \& Lindblad (2018). Immigrant student achievement and education policy in Sweden. In L. Volante et al. (eds.), Immigrant Student Achievement and Education Policy, Policy Implications of Research in Education 9, 69-86, Springer International Publishing AG, https://doi.org/10.1007/978-3-319-74063-8 5

Maasalo, K., Lindblom, J., Kiviruusu, O., Santalahti, P., \& Aronen, E. T. (2020). Longitudinal associations between inhibitory control and externalizing and internalizing symptoms in school-aged children. Development and Psychopathology, 33(3), 843-55. https://doi.org/10.1017/S0954579420000176

Martinussen, R., Hayden, J., Hogg-Johnson, S., \& Tannock, R. (2005). A meta-analysis of working memory impairments in children with attention-deficit/hyperactivity disorder. Journal of the American Academy of Child and Adolescent Psychiatry, 44, 377-84. https://doi.org/10.1097/01.chi.0000153228.72591.73

Menting, B., van Lier, P. A. C., \& Koot, H. M. (2010). Language skills, peer rejection, and the development of externalizing behavior from kindergarten to fourth grade. Journal of Child Psychology and Psychiatry, 52(1), 72-9. https://doi.org/10.1111/j.14697610.2010.02279.x

Milcher, S. (2006). Poverty and the determinants of welfare for Roma and other vulnerable groups in southeastern Europe. Comparative Economic Studies, 48(1), 20-35. https://doi.org/10.1057/palgrave.ces.8100148

MKFFI - Ministerium für Kinder, Familie, Flüchtlinge und Integration des Landes Nordrhein-Westfalen (2019). The practice of accomodation for asylum-seekers. Verfahren zur Unterbringung von Asylbewerbern. https://www.mkffi.nrw/verfahren-zurunterbringung-von-asylbewerbern 
Nelson, Benner, Neill, \& Stage (2006). Interrelationships among language skills, externalizing behavior, and academic fluency and their impact on the academic skills of students with ED. Journal of Emotional and Behavioral Disorders, 14(4), 209-16. https://doi.org/10.1177/10634266060140040401

Özmen Z. K. (2020). The problems that Syrian refugee children, class teachers and Turkish children face in the school environment from the standpoint of trainee teachers. Educational Research and Reviews, 15(9), 554-63. https://doi.org/10.5897/ERR2020.3959

Pellizzoni, S., Apuzzo, G. M., Vita, C. de, Agostini, T., Ambrosini, M., \& Passolunghi, M. C. (2020). Exploring EFs and math abilities in highly deprived contexts. Frontiers in Psychology, 11, 383. https://doi.org/10.3389/fpsyg.2020.00383

Petermann, F., \& Lipsius, M. (Eds.). (2009). Wechsler Preschool and Primary Scale of Intelligence-III - Deutsche Version (WPPSI-III). Frankfurt am Main: Pearson.

Purpura, D. J., Schmitt, S. A., \& Ganley, C. M. (2017). Foundations of mathematics and literacy: The role of executive functioning components. Journal of Experimental Child Psychology, 153, 15-34. http://dx.doi.org/10.1016/j.jecp.2016.08.010

Roebers, C. M., Röthlisberger, M., Neuenschwander, R., Cimeli, P., Michel, E., \& Jäger, K. (2014). The relation between cognitive and motor performance and their relevance for children's transition to school: A latent variable approach. Human Movement Science, 33, 284-97. https://doi.org/10.1016/j.humov.2013.08.011

Séguin, J.R., Parent, S., Tremblay, R.E., \& Zelazo, P.D. (2009). Different neurocognitive functions regulating physical aggression and hyperactivity in early childhood. Journal of Child Psychology and Psychiatry, 50, 679-687. https://doi.org/10.1111/j.1469$\underline{7610.2008 .02030 . x}$

Sim, A., Bowes, L., \& Gardner, F. (2018). Modeling the effects of war exposure and daily stressors on maternal mental health, parenting, and child psychosocial adjustment: A crosssectional study with Syrian refugees in Lebanon. Global Mental Health, 5, e40. https://doi.org/10.1017/2Fgmh.2018.33

Solari, C. D., \& Mare, R. D. (2012). Housing crowding effects on children's wellbeing. Social Science Research, 41(2), 464-76. https://doi.org/10.1016/j.ssresearch.2011.09.012 
Stevenson, J., \& Willott, J. (2007). The aspiration and access to higher education of teenage refugees in the UK. Compare: A Journal of Comparative and International Education, 37(5), 671-87. https://doi.org/10.1080/03057920701582624

Strauß, D. (2021). RomnoKher Study 2021: Unequal participation. The situation of Sinti and Roma in Germany. RomnoKher-Studie 2021: Ungleiche Teilhabe. Zur Lage der Sinti und Roma in Deutschland. Mannheim: RomnoKher.

Taylor, Z. E., Ruiz, Y., \& Nair, N. (2019). A mixed-method examination of ego-resiliency, adjustment problems, and academic engagement in children of Latino migrant farmworkers. Social Development, 28(1), 200-17. https://doi.org/10.1111/sode.12328

Tran, C. D., Arredondo, M. M., \& Yoshida, H. (2019). Early executive function: The influence of culture and bilingualism. Bilingualism: Language and Cognition, 22(04), 714-32. https://doi.org/10.1017/S1366728918000160

Wang, Y., \& Liu, Y. (2020). The development of internalizing and externalizing problems in primary school: Contributions of executive function and social competence. Child Development, 92(3), 889-903. https://doi.org/10.1111/cdev.13462

Woerner, W., Becker, A. \& Rothenberger, A. (2004). Normative data and scale properties of the German parent SDQ. European Child \& Adolescent Psychiatry, 13, ii3-10. https://doi.org/10.1007/s00787-004-2002-6

Wong, C. W. S., \& Schweitzer, R. D. (2017). Individual, premigration and postsettlement factors, and academic achievement in adolescents from refugee backgrounds: A systematic review and model. Transcultural Psychiatry, 54(5), 756-82.

https://doi.org/10.1177/1363461517737015

Zwi, K., Woodland, L., Williams, K., Palasanthiran, P., Rungan, S., Jaffe, A., \& Woolfenden, S. (2018). Protective factors for social-emotional well-being of refugee children in the first three years of settlement in Australia. Archives of Disease in Childhood, 103, 261-8. https://doi.org/10.1136/archdischild-2016-312495 
Table 1

Descriptive information on children in the three groups and the subsample

Frequency by study group $(\%)$

\begin{tabular}{llcccc} 
& & Immigrant & Refugee & Roma & Subsample \\
\hline $\begin{array}{c}\text { Preschool attendance }{ }^{1} \\
(n=49 ; 83 ; 88 ; 78)\end{array}$ & & & & & \\
Literacy of parents & Both parents & 93.88 & 55.17 & 35.23 & 39.74 \\
$(n=44 ; 67 ; 57 ; 46)$ & One parent & 88.64 & 64.29 & 42.11 & 43.48 \\
Number of siblings & None or one & 11.36 & 34.29 & 29.83 & 36.96 \\
$(n=52 ; 95 ; 93 ; 68)$ & Two or three & 32.69 & 33.33 & 31.19 & 33.82 \\
& Four or more & 55.77 & 58.58 & 39.78 & 41.18
\end{tabular}

Note. $n=$ number of cases. Subsample refers to children with available academic learning skills data. ${ }^{1}$ Either abroad or in Germany. 
Table 2

Descriptive information on the socio-emotional problems of the study groups

\begin{tabular}{|c|c|c|c|c|c|c|c|c|c|c|c|c|}
\hline & \multicolumn{3}{|c|}{ Immigrant } & \multicolumn{3}{|c|}{ Refugee } & \multicolumn{3}{|c|}{ Roma } & \multirow{2}{*}{$\begin{array}{r}\text { Norm }^{1} \\
\text { Cutoff } \\
\end{array}$} & \multicolumn{2}{|c|}{ Subsample } \\
\hline & $M$ & $S D$ & Cutoff & $M$ & $S D$ & Cutoff & $M$ & $S D$ & Cutoff & & $M$ & $S D$ \\
\hline Hyperactivity/inattention & 3.0 & 2.88 & 14.3 & 3.55 & 2.96 & 17.8 & 4.38 & 2.99 & 28.6 & 9.8 & 4.05 & 2.88 \\
\hline Conduct problems & 0.91 & 1.79 & 7.9 & 1.63 & 1.96 & 9.9 & 1.80 & 2.19 & 11.6 & 6.6 & 1.70 & 2.48 \\
\hline Emotional symptoms & 1.61 & 2.48 & 10.7 & 1.57 & 2.03 & 10.9 & 2.19 & 2.70 & 16.1 & 7.7 & 2.29 & 2.72 \\
\hline Peer relationship problems & 1.18 & 1.40 & 1.8 & 1.73 & 1.99 & 8.9 & 2.16 & 2.08 & 14.3 & 7.0 & 1.83 & 2.00 \\
\hline Prosocial behavior & 7.96 & 1.92 & 14.9 & 7.39 & 2.36 & 14.9 & 7.13 & 2.67 & 17.9 & 7.1 & 7.42 & 2.46 \\
\hline Total difficulties score & 6.70 & 6.16 & 10.7 & 8.50 & 6.50 & 8.9 & 10.50 & 6.94 & 25.0 & 10.0 & 9.87 & 7.46 \\
\hline
\end{tabular}

Note. $M=$ mean. $S D=$ standard deviation. ${ }^{1}$ German norm data (Woerner et al., 2004). Cutoff indicates proportions of children scoring above the cutoff threshold for abnormal problems or prosocial behavior according to German norm data. 
Table 3

Subsample: Descriptive information on academic learning skills

\begin{tabular}{lrrrrrrr} 
& \multicolumn{1}{c}{$M$} & \multicolumn{1}{c}{$\begin{array}{c}\text { Far below } \\
\text { average }\end{array}$} & $\begin{array}{c}\text { Below } \\
\text { average }\end{array}$ & $\begin{array}{c}\text { Above } \\
\text { Average }\end{array}$ & $\begin{array}{c}\text { Far above } \\
\text { average } \\
\text { average }\end{array}$ \\
\hline Receptive vocabulary $(\mathrm{n}=$ & 74.56 & 32.19 & 77.8 & 19.8 & 2.5 & - & - \\
81) & & & & & & & \\
Gross motor skills $(\mathrm{n}=82)$ & 7.59 & 2.18 & 3.7 & 18.3 & 73.2 & 4.9 & - \\
Fine motor skills $(\mathrm{n}=83)$ & 8.23 & 1.38 & 3.6 & 20.5 & 75.9 & - & - \\
Visuo-motor skills $(\mathrm{n}=83)$ & 7.17 & 2.73 & 27.7 & 34.9 & 37.3 & - & - \\
Cognitive reasoning $(\mathrm{n}=81)$ & 38.83 & 15.24 & 3.7 & 16.0 & 46.9 & 33.3 & - \\
Executive Functioning $(\mathrm{n}=$ & 0.79 & 0.24 & - & - & - & - & - \\
$83)$ & & & & & & & - \\
\hline
\end{tabular}

Note. $M=$ mean. $S D=$ standard deviation. Relative numbers of children (\%) per norm-referenced category. 
Table 4

$S D Q$ sample: Hierarchical regression analysis for group differences in $S D Q$ subscales

Hyperactivity/Inattention

Model 1

Model 2

\begin{tabular}{|c|c|c|c|c|c|c|c|c|}
\hline & & \multicolumn{4}{|c|}{18} \\
\hline & $B$ & $S E$ & $t$ & $p$ & $B$ & $S E$ & $t$ & $p$ \\
\hline Age & -0.044 & 0.013 & -3.420 & $<.001$ & -0.047 & 0.013 & -3.758 & $<.001$ \\
\hline Gender & 1.532 & 0.349 & 4.390 & $<.001$ & 1.646 & 0.344 & 4.789 & $<.001$ \\
\hline Mig-Ref ${ }^{1}$ & & & & & 0.560 & 0.468 & 1.196 & .233 \\
\hline Mig-Roma ${ }^{2}$ & & & & & 1.629 & 0.459 & 3.551 & $<.001 * * *$ \\
\hline Ref-Roma $^{3}$ & & & & & 1.068 & 0.387 & 2.762 & $.006 * *$ \\
\hline$R^{2}$ & \multicolumn{4}{|c|}{$R^{2}=.101, F(2,265)=14.940, p<.001$} & \multicolumn{4}{|c|}{$\Delta R^{2}=.029, F(2,263)=7.391, p<.001$} \\
\hline
\end{tabular}

Conduct Problems

Model 1

Model 2

\begin{tabular}{|c|c|c|c|c|c|c|c|c|}
\hline & $B$ & $S E$ & $t$ & $p$ & $B$ & $S E$ & $t$ & $p$ \\
\hline Age & 0.004 & 0.009 & 0.476 & .635 & 0.002 & 0.009 & 0.213 & .831 \\
\hline Gender & 0.860 & 0.244 & 3.526 & $<.001$ & 0.890 & 0.243 & 3.663 & $<.001$ \\
\hline Mig-Ref & & & & & 0.623 & 0.331 & 1.882 & .061 \\
\hline Mig-Roma & & & & & 0.934 & 0.324 & 2.882 & $.004 * *$ \\
\hline Ref-Roma & & & & & 0.311 & 0.273 & 1.139 & .256 \\
\hline$R^{2}$ & \multicolumn{4}{|c|}{$R^{2}=.046, F(2,265)=6.400, p=.002$} & \multicolumn{4}{|c|}{$\Delta R^{2}=.029, F(2,263)=4.154, p=.017$} \\
\hline
\end{tabular}

Emotional Symptoms

\begin{tabular}{|c|c|c|c|c|c|c|c|c|}
\hline & \multicolumn{4}{|c|}{ Model 1} & \multicolumn{4}{|c|}{ Model 2} \\
\hline & $B$ & $S E$ & $t$ & $p$ & $B$ & $S E$ & $t$ & $p$ \\
\hline Age & -0.020 & 0.011 & -1.894 & .059 & -0.021 & 0.011 & -2.000 & .047 \\
\hline Gender & -0.988 & 0.290 & -3.408 & $<.001$ & -0.938 & 0.292 & -3.216 & .001 \\
\hline Mig-Ref & & & & & 0.139 & 0.397 & 0.349 & .727 \\
\hline Mig-Roma & & & & & 0.601 & 0.389 & 1.544 & .124 \\
\hline Ref-Roma & & & & & 0.462 & 0.328 & 1.408 & .160 \\
\hline$R^{2}$ & \multicolumn{4}{|c|}{$R^{2}=.056, F(2,265)=7.853, p<.001$} & \multicolumn{4}{|c|}{$\Delta R^{2}=.011, F(2,263)=1.567, p=.211$} \\
\hline
\end{tabular}

Peer Problems

Model 1

Model 2

\begin{tabular}{|c|c|c|c|c|c|c|c|c|}
\hline \multirow{2}{*}{ 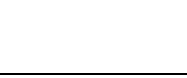 } & & \\
\hline & $B$ & $S E$ & $t$ & $p$ & $B$ & $S E$ & $t$ & $p$ \\
\hline Age & -0.028 & 0.009 & -3.305 & .001 & -0.029 & 0.009 & -3.414 & $<.001$ \\
\hline Gender & 0.434 & 0.233 & 1.860 & .064 & 0.479 & 0.231 & 2.074 & .039 \\
\hline Mig-Ref & & & & & 0.632 & 0.314 & 2.011 & $.045 *$ \\
\hline Mig-Roma & & & & & 1.074 & 0.309 & 3.490 & $<.001 * * *$ \\
\hline Ref-Roma & & & & & 0.442 & 0.260 & 1.705 & $.089 *$ \\
\hline$R^{2}$ & \multicolumn{4}{|c|}{$R^{2}=.050, F(2,265)=6.972, p=.001$} & \multicolumn{4}{|c|}{$\Delta R^{2}=.042, F(2,263)=6.151, p=.002$} \\
\hline
\end{tabular}


Prosocial Problems

Model 1

\begin{tabular}{|c|c|c|c|c|c|c|c|c|}
\hline & $B$ & $S E$ & $t$ & $p$ & $B$ & $S E$ & $t$ & $p$ \\
\hline Age & 0.018 & 0.010 & 1.747 & 0.0817 & 0.020 & 0.010 & 1.981 & .049 \\
\hline Gender & -1.507 & 0.282 & -5.336 & $<.001$ & -1.555 & 0.282 & -5.514 & $<.001$ \\
\hline Mig-Ref & & & & & -0.523 & 0.384 & -1.361 & .175 \\
\hline Mig-Roma & & & & & -0.990 & 0.384 & -2.632 & $.009 *$ \\
\hline Ref-Roma & & & & & -0.467 & 0.317 & -1.473 & .142 \\
\hline$R^{2}$ & \multicolumn{4}{|c|}{$R^{2}=.104, F(2,265)=15.440, p<.001$} & \multicolumn{4}{|c|}{$\Delta R^{2}=.024, F(2,263)=3.573, p=.029$} \\
\hline
\end{tabular}

Note. $B=$ unstandardized regression coefficient. $S E=$ standard error of $B . t=t$-value. $p=$ two-tailed, uncorrected $p$-values. $\Delta R^{2}=$ incremental variance explained by group. Gender: $0=$ female, $1=$ male. Only $p$ values in bold were part of hypothesis testing. For those, asterisks indicate significance based on one-tailed testing with Bonferroni-Holm correction. Groups were dummy-coded.

${ }^{1}$ Group difference between immigrant (Mig) and refugee children (Ref).

${ }^{2}$ Group difference between immigrant (Mig) and Roma children (Roma).

${ }^{3}$ Group difference between refugee (Ref) and Roma children (Roma).

$* p<.05, * * p<.01, * * * p<.001$. 
Table 5

Subsample: Hierarchical regression analysis for influences of SDQ scores on academic competences

Receptive vocabulary

\begin{tabular}{|c|c|c|c|c|c|c|c|c|}
\hline & \multicolumn{4}{|c|}{ Model 1} & \multicolumn{4}{|c|}{ Model 2} \\
\hline & $B$ & $S E$ & $t$ & $p$ & $B$ & $S E$ & $t$ & $p$ \\
\hline Age & 0.957 & 0.238 & 4.021 & $<.001$ & 0.905 & 0.244 & 3.710 & $<.001$ \\
\hline Gender & 8.764 & 6.841 & 1.281 & .204 & 10.496 & 6.977 & 1.504 & .137 \\
\hline Нyp & & & & & -2.036 & 1.631 & -1.248 & .216 \\
\hline Cond & & & & & 2.513 & 2.089 & 1.203 & .233 \\
\hline Emot & & & & & 0.168 & 1.540 & 0.109 & .914 \\
\hline Peer & & & & & 2.933 & 1.989 & 1.475 & .145 \\
\hline Pros & & & & & 3.574 & 1.862 & 1.919 & .059 \\
\hline$R^{2}$ & \multicolumn{4}{|c|}{$R^{2}=.221, F(2,75)=10.62, p<.001$} & \multicolumn{4}{|c|}{$\Delta R^{2}=.070, F(5,70)=1.380, p=.242$} \\
\hline
\end{tabular}

Gross motor skills

Model 1

Model 2

\begin{tabular}{lcccccccc} 
& $B$ & $S E$ & $t$ & $p$ & $B$ & $S E$ & $t$ & $p$ \\
\cline { 2 - 9 } Age & 0.070 & 0.016 & 4.277 & $<.001$ & 0.067 & 0.017 & 3.909 & $<.001$ \\
Gender & -0.309 & 0.470 & -0.656 & .514 & -0.344 & 0.491 & -0.700 & .486 \\
Hyp & & & & & -0.081 & 0.113 & -0.716 & $\mathbf{. 4 7 6}$ \\
Cond & & & & & 0.145 & 0.149 & 0.978 & $\mathbf{. 3 3 2}$ \\
Emot & & & & 0.040 & 0.106 & 0.379 & $\mathbf{. 7 0 6}$ \\
Peer & & & 0.112 & 0.137 & 0.815 & $\mathbf{. 4 1 8}$ \\
Pros & & & 0.098 & 0.129 & 0.764 & $\mathbf{. 4 4 7}$ \\
$R^{2}$ & & & & \multicolumn{5}{c}{$\Delta R^{2}=.026, F(5,71)=0.475, p=.793$} \\
\hline
\end{tabular}

Fine motor skills

\begin{tabular}{lcccccccc} 
& \multicolumn{9}{c}{ Model 1 } & \multicolumn{6}{c}{ Model 2 } \\
\cline { 2 - 9 } & $B$ & $S E$ & $t$ & $p$ & $B$ & $S E$ & $t$ & $p$ \\
\hline Age & 0.036 & 0.010 & 3.457 & .001 & 0.027 & 0.010 & 2.619 & .011 \\
Gender & -0.926 & 0.297 & -3.119 & .003 & -0.993 & 0.294 & -3.375 & .001 \\
Hyp & & & & & -0.027 & 0.068 & -0.390 & $\mathbf{. 6 9 8}$ \\
Cond & & & & 0.161 & 0.089 & 1.810 & $\mathbf{. 0 7 5}$ \\
Emot & & & & 0.116 & 0.064 & 1.806 & $\mathbf{. 0 7 5}$ \\
Peer & & & -0.022 & 0.083 & -0.269 & $\mathbf{. 7 8 9}$ \\
Pros & & & 0.212 & 0.078 & 2.710 & $\mathbf{. 0 0 8 *}$ \\
$R^{2}$ & & & & & $\Delta R^{2}=.107, F(5,72)=2.165, p=.067$ \\
\hline
\end{tabular}

Visuo-motor skills

Model 1

Model 2

\begin{tabular}{lcccccccc} 
& $B$ & $S E$ & $t$ & $p$ & $B$ & $S E$ & $t$ & $p$ \\
\hline Age & 0.059 & 0.021 & 2.745 & .008 & 0.051 & 0.023 & 2.224 & .029 \\
Gender & -0.516 & 0.620 & -0.833 & .407 & -0.441 & 0.649 & -0.679 & .500
\end{tabular}




\begin{tabular}{|c|c|c|c|c|c|c|c|c|}
\hline Нyp & & & & & -0.093 & 0.150 & -0.622 & .536 \\
\hline Cond & & & & & -0.007 & 0.197 & -0.033 & .974 \\
\hline Emot & & & & & 0.126 & 0.142 & 0.886 & .379 \\
\hline Peer & & & & & 0.027 & 0.184 & 0.149 & .882 \\
\hline Pros & & & & & 0.093 & 0.172 & 0.538 & .592 \\
\hline$R^{2}$ & \multicolumn{4}{|c|}{$R^{2}=.089, F(2,77)=3.778, p=.027$} & \multicolumn{4}{|c|}{$\Delta R^{2}=.027, F(5,72)=0.434, p=.823$} \\
\hline \multicolumn{9}{|c|}{ Cognitive operation } \\
\hline & \multicolumn{4}{|c|}{ Model 1} & \multicolumn{4}{|c|}{ Model 2} \\
\hline & $B$ & $S E$ & $t$ & $p$ & $B$ & $S E$ & $t$ & $p$ \\
\hline Age & 0.245 & 0.122 & 2.006 & .049 & 0.160 & 0.126 & 1.271 & .208 \\
\hline Gender & 1.154 & 3.541 & 0.326 & .745 & 1.415 & 3.540 & 0.400 & .691 \\
\hline Нyp & & & & & -1.526 & 0.825 & -1.850 & .069 \\
\hline Cond & & & & & 0.269 & 1.118 & 0.241 & .811 \\
\hline Emot & & & & & 1.483 & 0.772 & 1.922 & .059 \\
\hline Peer & & & & & 0.694 & 1.012 & 0.686 & .495 \\
\hline Pros & & & & & 0.683 & 0.935 & 0.730 & .468 \\
\hline$R^{2}$ & \multicolumn{4}{|c|}{$R^{2}=.059, F(2,75)=2.337, p=.104$} & \multicolumn{4}{|c|}{$\Delta R^{2}=.105, F(5,70)=1.761, p=.132$} \\
\hline
\end{tabular}

Executive function

\begin{tabular}{|c|c|c|c|c|c|c|c|c|}
\hline & \multicolumn{4}{|c|}{ Model 1} & \multicolumn{4}{|c|}{ Model 2} \\
\hline & $B$ & $S E$ & $t$ & $p$ & $B$ & $S E$ & $t$ & $p$ \\
\hline Age & 0.007 & 0.002 & 4.190 & $<.001$ & 0.007 & 0.002 & 4.017 & $<.001$ \\
\hline Gender & 0.072 & 0.050 & 1.459 & .149 & 0.064 & 0.052 & 1.241 & .219 \\
\hline Нyp & & & & & -0.006 & 0.012 & -0.481 & .632 \\
\hline Cond & & & & & 0.005 & 0.016 & 0.308 & .759 \\
\hline Emot & & & & & 0.006 & 0.011 & 0.488 & .627 \\
\hline Peer & & & & & -0.018 & 0.015 & -1.213 & .229 \\
\hline Pros & & & & & -0.013 & 0.014 & -0.952 & .344 \\
\hline$R^{2}$ & \multicolumn{4}{|c|}{$R^{2}=.239, F(2,77)=12.12, p<.001$} & \multicolumn{4}{|c|}{$\Delta R^{2}=.027, F(5,72)=0.534, p=.750$} \\
\hline
\end{tabular}

Note. $B=$ unstandardized regression coefficient. $S E=$ standard error of $B . t=t$-value. $p=$ two-tailed, uncorrected $p$-values. $\Delta R^{2}=$ incremental variance explained by group. Gender: $0=$ female, $1=$ male. Only $p$-values in bold were part of hypothesis testing. For those, asterisks indicate significance based on one-tailed testing with Bonferroni-Holm correction. Hyp = hyperactivity / inattention. Cond = conduct problems. Emot = emotional symptoms. Peer $=$ peer relationship problems. Pros $=$ prosocial behavior.

${ }^{*} \mathrm{p}<.05$. 


\section{Table 6}

Subsample: Correlation matrix for socio-emotional problems and academic learning skills

\begin{tabular}{|c|c|c|c|c|c|c|c|c|c|c|c|c|c|}
\hline Variable & Age & Gender & Нyp & Cond & Emot & Peer & Pros & PPVT & $\mathrm{CR}$ & GM & FM & $\mathrm{VM}$ & $\mathrm{EF}$ \\
\hline Age & 1. & & & & & & & & & & & & \\
\hline Gender & 0.25 & 1. & & & & & & & & & & & \\
\hline Нyр & -0.01 & 0.16 & 1. & & & & & & & & & & \\
\hline Cond & -0.03 & 0.18 & 0.67 & 1. & & & & & & & & & \\
\hline Emot & 0.16 & 0.18 & 0.31 & 0.18 & 1. & & & & & & & & \\
\hline Peer & -0.03 & 0.03 & 0.46 & 0.44 & 0.30 & 1. & & & & & & & \\
\hline Pros & 0.14 & -0.08 & -0.53 & -0.69 & -0.13 & -0.37 & 1. & & & & & & \\
\hline PPVT & 0.43 & 0.23 & -0.06 & 0.00 & 0.15 & 0.05 & 0.19 & 1. & & & & & \\
\hline $\mathrm{CR}$ & 0.23 & 0.09 & -0.19 & -0.14 & 0.25 & 0.00 & 0.19 & 0.28 & 1. & & & & \\
\hline GM & 0.45 & 0.05 & 0.00 & 0.07 & 0.14 & 0.09 & 0.06 & 0.19 & 0.21 & 1. & & & \\
\hline FM & 0.30 & -0.24 & -0.06 & -0.05 & 0.11 & 0.01 & 0.26 & 0.05 & 0.25 & $0.37 * *$ & 1. & & \\
\hline VM & 0.30 & -0.02 & -0.11 & -0.11 & 0.12 & -0.03 & 0.15 & $0.37 * *$ & $0.50 * * *$ & $0.37 * *$ & 0.27 & 1. & \\
\hline $\mathrm{EF}$ & 0.46 & 0.26 & 0.00 & 0.04 & 0.10 & -0.10 & -0.02 & 0.18 & 0.23 & $0.35^{*}$ & 0.08 & 0.19 & 1. \\
\hline
\end{tabular}

prosocial behavior. PPVT = receptive vocabulary. $\mathrm{CR}=$ cognitive reasoning. GM, FM, VM= Gross, fine, visuo-motor skills. EF $=$ executive functioning We used point-

biserial correlation for gender, Pearson's correlation coefficient for all other variables. We only tested correlations between PPVT, CR, GM, FM, VM and EF for significance.

${ }^{*} \mathrm{p}<.05, * * \mathrm{p}<.01, * * * \mathrm{p}<.001$. 